\title{
Diabetes, diet and dental caries
}

\author{
V. P. Hariharavel ${ }^{1} \cdot$ Arun Prasad V. Rao $^{2} \cdot$ Reddy N. Venugopal $^{3} \cdot$ Joby Peter $^{4}$
}

Received: 23 May 2013 / Accepted: 6 May 2015 / Published online: 19 May 2015

(C) Research Society for Study of Diabetes in India 2015

\section{Dear Sir,}

Prevalence of diabetes in India is rising in astronomical proposition, so does its complication. Oral cavity is no exception. The risk of developing complications is significantly reduced by healthy eating, regular physical activity and having wellcontrolled blood glucose levels. Since the consumption of simple or refined carbohydrates like sucrose increases the blood glucose levels quickly, the dietary practice of consuming complex carbohydrates has a great role in having wellcontrolled blood glucose levels and development of longterm complication in diabetic patient.

Therefore, from the dental perspective, one could expect that such dietary practice of lower intake of refined carbohydrates not to favour the growth of cariogenic bacteria and the subsequent development of carious lesions in diabetics [1]. But the incidence of dental caries in diabetics is higher when compared to non-diabetics. This is surprising in view of the fact that the lower intake of refined carbohydrates, especially sucrose, and high protein content of the diet make the diabetic subjects clearly less cariogenic than among non-diabetics. This difference can be attributed to the complications of diabetes which are based on microvascular and macrovascular changes.

V. P. Hariharavel

vph.pedodontist@gmail.com

Arun Prasad V. Rao

apraprapr@gmail.com

Reddy N. Venugopal

drnvenugopalreddy@gmail.com

Joby Peter

jobspeter77@gmail.com

1 Department of Pedodontics and Preventive Dentistry, SRM

Kattankulathur Dental College and Hospital, Chennai, India

2 Department of Pedodontics and Preventive Dentistry, Mahatma Gandhi Post Graduate Institute of Dental Sciences,

Pondicherry 605006, India

3 Department of Pedodontics and Preventive Dentistry, Mamata Dental College and Hospital, Khammam 507002, India

4 Department of Pedodontics and Preventive Dentistry, Rajah Muthiah Dental College and Hospital, Chidambaram, India
Normal salivary function is essential to the preservation of the integrity of teeth and oral soft tissues. Salivary glands act as a filter of blood glucose that would be altered by hormonal or neural regulation [2]. But microvascular damage alters basement membrane in salivary gland, leading to increased leakage of glucose from ductal cells. This results in increased glucose levels in saliva and crevicular fluid which causes decreased fibroblastic activity which in turn produces increased plaque accumulation. The glucose released into the saliva is metabolized to lactic acid by plaque. This results in decreased salivary $\mathrm{pH}$ and increases acidophilic bacteria. Long-term glucose leakage into saliva is likely to increase the metabolic activity of the oral microflora. This changes the natural balance of the dental biofilm [3] and causes dental decay and periodontal diseases.

The acidic $\mathrm{pH}$ of saliva in diabetics may be associated either to microbial activity or to decreased levels of bicarbonate with decreased salivary flow rate. So, when treating diabetic patients, practitioners should be alert to complaints of dry mouth and signs of decreased salivary function. Hyosalivation may be indicative of poor glycemic control in some of these patients [4].

Lack of patient knowledge on the association of oral health with maintaining metabolic control of diabetes is a significant challenge to prevent the oral health complications. Hence, children and adolescents with poorly controlled or uncontrolled diabetes exhibit higher incidence of caries inspite of extensive preventive efforts.

\section{References}

1. Tenovuo J, Alanen P, Larjava H, Viikari J, Lehtonen OP. Oral health of patients with insulin-dependent diabetes mellitus. Scand J Dent Res. 1986;94:338-46.

2. Aren G, Sepet E, Ozdemir D, Dinççağ N, Güvener B, Firatli E. Periodontal health, salivary status and metabolic control in children with type 1 diabetes mellitus. J Periodontol. 2003;74:1789-95.

3. Siudikiene J, Machiulskiene V, Nyvad B, Tenovuo J, Nedzelskiene I. Dental caries increments and related factors in children with type 1 diabetes mellitus. Caries Res. 2008;42:354-62.

4. Moore PA, Guggenheimer J, Etzel KR, Weyant RJ, Orchard T. Type 1 diabetes mellitus, xerostomia, and salivary flow rates. Oral Surg Oral Med Oral Pathol Oral Radiol Endod. 2001;92: 281-91. 